\title{
Pelatihan Teknologi Pengeleman kayu dalam Air untuk Sampan Nelayan
}

\author{
Mansyur Hasbullah*, Moh. Rizal Firmansyah, Misliah, Abdul Haris Djalante, \\ Suandar Baso, Sitti Chaerunnisa, Hamzah, Andi Mursid Nugraha, \\ Andi Dian Ekawati, Muhammad Uswah Pawara, Ardedi Yusuf dan Alwan \\ Departemen Teknik Perkapalan, Fakultas Teknik Universitas Hasanuddin \\ mansyur_hasbullah@yahoo.com*
}

\begin{abstract}
Abstrak
Sampan sebagai alat transportasi pengangkut ikan dari perahu nelayan yang berfungsi untuk menampung dan menangkap ikan di laut lepas. Ikan hasil tangkapan nelayan ini dibawa ke daratan untuk di pasarkan. Dengan kemampuan angkut yang ukuranya sekitar 0,05 GT atau 0,03 GT umumnya tanpa mesin penggerak, peran sampan ini sangat strategis karena tanpa keberadaannya sebagai pembantu perahu nelayan maka akan beresiko terhadap muatan dalam perahu tersebut. Dari hasil pemantauan di lapangan menunjukkan bahwa kadang-kadang sapan mengalami kebocoran saat beroperasi mengangkut ikan. Untuk perbaikan kembali pada papan kulit sampan harus di bawa ke daratan dengan muatan kosong. Teknologi pengeleman kayu dalam air ini akan dapat mengatasi kondisi ini, karena pengeleman sampan dilakukan di saat muatan dalam sampan, tanpa harus dikosongkan/dipindahkan muatan tersebut. Performance lem propant ini akan dapat diketahui bila dilakukan hubungan antara luas permukaan kayu yang berbeda dan mempunyai tebal lem yang bervariasi maka menimbulkan tegangan geser yang berbeda pula. Dari hasil pengetesan pada komponen kayu yang menunjukkan bahwa dengan tebal lem antara 0,01 cm sampai $0,02 \mathrm{~cm}$ dengan luas pengeleman $(2.4 \times 1.9 \mathrm{~cm})$ dibandingkan dengan tebal lem dan luas permukaan pengeleman yang lebih besar telah menunjukkan keungguan dan efisien, karena dengan ketebalan rendah mampu menahan tegangan geser sebesar $662,5 \mathrm{~kg} / \mathrm{cm}^{4}$ dan dapat mengelem dan menyambung kayu kulit sampan $\mathrm{cm}^{2}$ yang dalam waktu pengeringan sambung \pm 3 jam dari kondisi air dan udara yang normal.
\end{abstract}

Kata Kunci: Sampan; Kapal Ikan; Lem Epoxi; Lem Propant; Tegangan Geser.

\begin{abstract}
The sampan as a transportation vehicle for transporting fish from fishing boats serves to collect and catch fish in the ground seas. These fish caught by fishermen are brought ashore to be marketed. With a carrying capacity of about 0.05 GT or 0.03 GT generally without a propulsion engine, the role of the canoe is very strategic because without its existence as a fishing boat aide there will be a risk to the cargo in the boat. From the results of monitoring in the field shows that sometimes sampan (canoe) experience leakage when operating transporting fish. For repairs to the leather boat the boat must be carried ashore with an empty load. The wood gluing technology in water will be able to overcome this condition, because the gluing of the canoe is carried out when the load is in the canoe, without having to empty / move the cargo. The performance of this propant glue will be known if there is a relationship between different wood surface areas and varying thicknesses of glue causing different shear stresses. From the results of testing on wood components that show that the thickness of the glue between $0.01 \mathrm{~cm}$ to $0.02 \mathrm{~cm}$ with a gluing area $(2.4 \times 1.9 \mathrm{~cm})$ compared to the thickness of the glue and a greater gluing surface area has shown superiority and efficiency, because with low thickness is able to withstand shear stress of $662.5 \mathrm{~kg} / \mathrm{cm} 4$ and can glue and connect the bark of the sampan cm 2 which in a continuous drying time \pm 3 hours from normal water and air conditions.
\end{abstract}

Keywords: Canoe; Fishing Boat; Epoxi Glue; Propant Glue; Shear Stress.

\section{Pendahuluan}

Secara administratif pemerintahan wilayah Kabupaten Takalar terdiri dari 7 kecamatan dan 77 desa/kelurahan yang terdiri dari 57 sesa serta 20 kelurahan. dari 7 kecamatan tersebut 4 kecamatan merupakan wilayah pesisir yaitu Mangarabombang dengan luas 100,50 km persegi 
terdiri dari 11 desa da 1 kelurahan, Mappakasunggu dengan luas 74, $63 \mathrm{~km}$ terdiri dari 7 desa 1 kelurahan, Galesong Selatan luas 44 terdiri dari 17 desa, Galesong Utara dengan luas 21,75 km persegi terdidi dari 9 desa. Tiga kecamatan lainnya adalah Polombangkeng Selatan, Polombangkeng Utara dan kecamatan Pattallassang.

Kecamatan Galesong secara geografi terletak di pesisir Kabupaten Takalar yang merupakan wilayah provinsi Sulawesi Selatan. daerah ini sangat mudah dijangkau dengan jarak $40 \mathrm{~km}$ dari kota metropolitan Makassar dan terletak antara 5 derajat 3 menit sampai 5 derajat 38 menit lintang selatan dan antara 199 derajat 22 menit sampai 199 derajat 39 mnit bujur timur dengan luas wilayah 566,51 km persegi.

Wilayah Galesong memanjang dari ujung desa Bontomarannu di selatan sampai baut-batu di utara berbatasan Barombong di Makassar. Secara administratif, Kabupaten Takalar memiliki batas-batas wilayah antara lain: (1) sebelah utara berbatasan dengan Kota Makassar dan kabupaten Gowa; (2) sebelah timur berbatasan dengan kabupaten Jeneponto; (3) sebeleh selatan berbatasan dengan laut Flores; (4) sebelah barat berbatasan dengan selat Makassar.

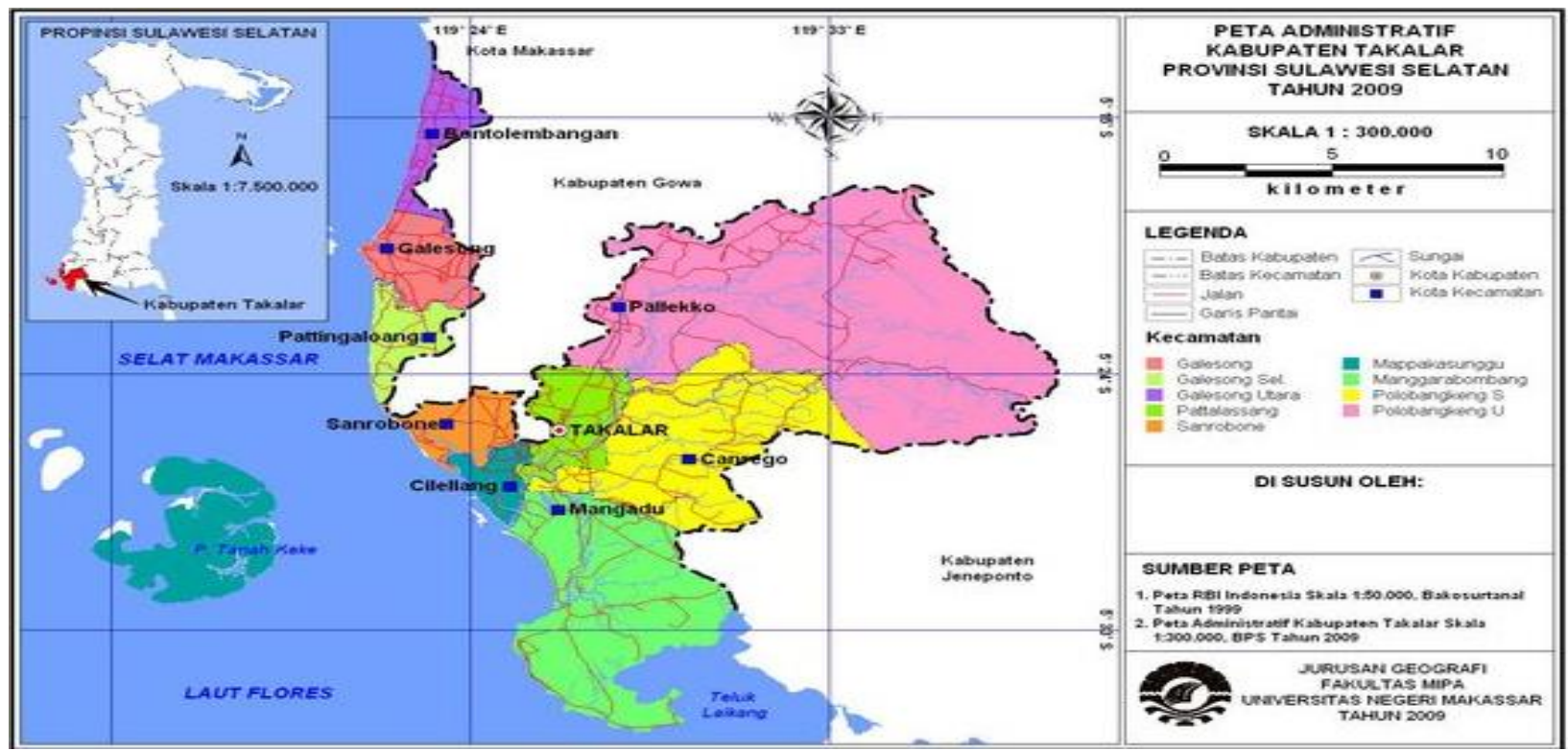

Gambar 1. Peta wilayah Kabupaten Takalar.

Mayoritas penduduk Kecamatan Galesong berprofesi sebagai Petani dan Nelayan disamping itu berprofesi sebagai pedagang dan usaha di sektor jasa. Salah satu kelompok nelayan yang masih eksis dan berkembang saat ini menghadapi masalah teknis yang menyangkut pengoperasian perahu dan sampan ikan mereka, kondisi sampan sebagai sarana angkutan ikan dari perahu untuk dibawa kedaratan, sering mengalami hambatan akibat sampan mereka bocor di papan lambung dan patah/lapuk di bagian gading-gading pada sambungan lunas.

Selama ini mereka memperbaiki kebocoran-kebocoran lambung dan gading-gading sampan dengan kondisi tanpa muatan atau barang. Akibatnya adalah waktu pengoperasian sampan terhambat untuk mendampingi perahu nelayan sebagai suplai muatan ikan yang akan dibawakan kedaratan (tempat pelelangan ikan di pesisir pantai) untuk mencegah kerusakan barang maupun muatan lainnya perlu adanya teknologi yang dapat membantu. 
Dengan teknologi pengeleman, propant ini bila digunakan untuk memperbaiki akan dan menambal sampan nelayan tersebut akan membantu peningkatan operasional sampan yang berimflikasi positif terhadap keuntungan (profitable effect) para nelayan.

Operasional perahu nelayan selalu didampingi oleh satu atau dua unit sampan yang tergantung pada ukuran dan GT perahu tersebut. Standar ukuran sampan biasanya (2,5- 3,5)m dengan berbagai type dan sesuai penggunaannya dilapangan, karena sampan sering digunakan untuk mengangkut, BBM, logistik maupun alat-alat perlengkapan untuk penangkapan dan penampungan ikan.

Peran sentral sampan pada masyarakat Nelayan di Kecamatan Galesong. Sampan pada awalnya dibuat dari batang utuh suatu pohon jenis kayu tertentu (kayu, pude, mahoni dan sebagainya) bukan jenis kayu yang mahal untuk perahu atau kapal. Tapi dengan perkembangan teknologi, konstruksi kapal kayu dan kesulitan mendapatkan batang kayu yang utuh juga sudah mahal, maka pengerajin perahu kayu memilih alternative lain dengan membangun sampan dengan konstruksi yang mempunyai lunas, gading-gading, haluan dan buritan. Bentuk ini menjadi tren sekarang karena mudah dibuat dan jenis harga murah dan banyak dipasaran.

\section{Ukuran dan Bentuk Sampan Kayu}

Ukuran dan bentuk sampan kayu biasanya mengacu pada induknya (perahu) dan biasanya dilakukan perbandingan yang rasional antara perahu (induk dengan sampan). Jadi konstruksi sampan yang ideal adalah kulit, gading-gading, lunas dengan haluan dan buritan.

Tabel 1. Ukuran perbandingan antara sampan perahu penangkap ikan dengan sampan perahu pengangkut barang

\begin{tabular}{|c|c|c|c|}
\hline A & B & A & B \\
perahu penangkap ikan & perahu muatan biasa & sampan ikan & sampan muatan \\
\hline Panjang x lebar x tinggi & Panjang x lebar x tinggi & Panjang x lebar x tinggi & Panjang x lebar x tinggi \\
P x L x T (m) & P x L x T (m) & P x L x T (m) & P x L $\times$ T (m) \\
\hline $7 \times 1,2 \times 0,9$ & $7 \times 1,8 \times 1,0$ & $3,5 \times 0,7 \times 0,45$ & $3,5 \times 0,8 \times 0,5$ \\
\hline
\end{tabular}

\subsection{Sampan kayu utuh tanpa gading-gading dan lembar papan kulit}

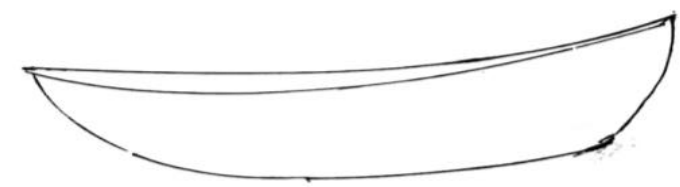

Gambar 2. Sampan kayu utuh 


\subsection{Sampan dengan gading-gading dan lembar papan kulit tanpa mesin}

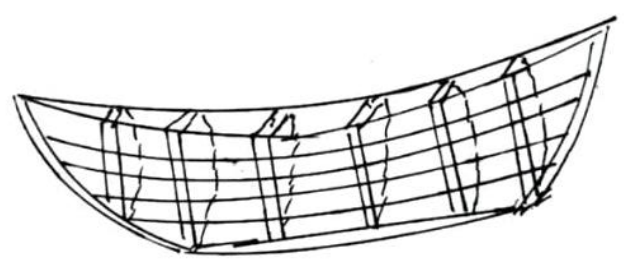

Gambar 3. Sampan dengan gading - gading

\subsection{Sampan dengan penggerak motor tempel}

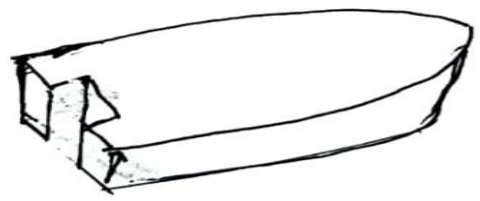

Gambar 4. Sampan dengan penggerak motor tempel

Tabel 2. Keuntungan dan kerugian dari 3 tipe sampan

\begin{tabular}{|c|c|c|}
\hline Type A & $\begin{array}{l}\text { Keuntungan : } \\
\text { 1. Jarang rusak pada badan kapal } \\
\text { 2. Tidak punya balok linggi, lunas }\end{array}$ & $\begin{array}{l}\text { Kerugian : } \\
\text { 1. Pemborosan bahan kayu } \\
\text { 2. Daya muat kurang } \\
\text { dibanding ukuran yang sama }\end{array}$ \\
\hline Type B & $\begin{array}{l}\text { Keuntungan : } \\
\text { 1. Mudah diperbaiki kalua papan } \\
\text { kulit dan gading rusak } \\
\text { 2. Ruang muat lebih besar } \\
\text { 3. Hemat bahan baku }\end{array}$ & $\begin{array}{l}\text { Kerugian : } \\
\text { 1. Papan kulit mudah rusak } \\
\text { bila terbentur } \\
\text { 2. Pemeliharaan lebih ketat }\end{array}$ \\
\hline Type C & $\begin{array}{l}\text { Keuntungan : } \\
\text { 1. Mobilisasi cepat karena ada mesin } \\
\text { 2. Ruangan muat lebih besar }\end{array}$ & $\begin{array}{l}\text { Kerugian : } \\
\text { 1. Biaya operasional tinggi } \\
\text { karena BBM } \\
\text { 2. Perawatan mesin dan badan } \\
\text { kapal bertambah }\end{array}$ \\
\hline
\end{tabular}




\section{Latar Belakang Teori}

\section{Tegangan Geser}

Penentuan besar tegangan geser menggunakan formula sebagai berikut

$$
\sigma=\frac{P}{A}
$$

$\sigma=$ Tegangan geser

$P=$ Besar tekanan geser

$A=$ Luas penampang Lem

\section{Metode}

\subsection{Lokasi Mitra dan Tempat Pelasanaan}

Lokasi kegiatan dilakukan di Kec. Galesong, Kab. Takalar, dimana sebagai mitra kerja adalah Bapak Muhammad Sayyid Dg. Ngampa. Beliau adalah ketua kelompok nelayan dan pembuat/perbaikan kapal/perahu.

\subsection{Metode Pendekatan}

Langkah awal kegiatan adalah melalui persuratan antara Tim Pengabdian pada masyarakat LBE Fakultas Teknik Universitas Hasanuddin dengan bapak Muhammad Sayyid Dg. Ngampa. Di dalam surat tersebut, telah dijelaskan tujuan kegiatan, sekalian memperkenalkan cara pengeleman dengan lem Epoxi propant. Mereka setuju dengan kegiatan ini dan melalui ketua kelompok nelayan melaluli telepon seluler (HP) dan disampaikan pula tentang jadwal waktu yang tepat dan tidak mengganggu kegiatan para nelayan tersebut.

Tempat pelaksanaan kegiatan ini adalah ruang kerja/bengkel di samping rumah bapak Muhammad Sayyid Dg. Ngampa. Rumah ini cukup representative, karena dilengkapi dengan mesin-mesin las, mesin bubut, trafo, pengisian aki, tempat duduk dan with board.

Pelaksanaan dilakukan 2 hari, dengan peserta lebih kurang 16 orang yaitu:

Dosen $/$ mahasiswa $=8$ Orang

Peserta $($ nelayan $)=8$ Orang

\subsection{Prosedur dan Rencana Kerja}

Prosedur-prosedur awal kegiatan adalah mengetahui latar belakang mereka termasuk pengalaman dan pendidikan mereka yang merangkap jadi nelayan dan pembuat kapal kayu. Umumnya, pendidikan adalah SMP ke atas, sebagai penjelasan dari pemaparan dari pekerjaan ini dapat dimengerti dengan baik oleh mereka karena berpengalaman tentang perahu dan sampan ikan.

\subsection{Rencana kerja}

Rencana kerja awal dari kegiatan adalah: Registrasi peserta; Bahasan teori pengecekan dan pengeleman dan penegecatan; Memperkenalkan jenis bahan kayu dan sampan; Menjelaskan 
tentang type lem dan manfaat bagi konstruksi kayu; Bahan kayu; Peralatan yang digunakan dalam pengeleman ini; Praktek pencampuran 2 jam lem propan agar hasilnya cukup; Praktek pemasangan lem propan di atas permukaan benda kerja (benda yang dilem); Bagaimana cara menghitung luas pengeleman dan tebal pengeleman sesuai barisan dari pabrik propan; Menghubungkan permukaan yang di lem dengan kayu pengeleman; Setelah lem ditempel pada kedua permukaan kayu selanjutnya di jepit dan di tekan dengan menempel dengan keras atau ketat; Tempelan kedua permukaan ini didiamkan selama satu sampai dua jam kemudian dibuka.

\subsection{Partisipasi Mitra dalam Kegiatan}

Partisipasi mitra dalam kegiatan ini adalah memberikan informasi kondisi aktual perahu dan sampan nelayan yang dioperasikan oleh mereka.

\section{Hasil dan Pembahasan}

\subsection{Survey awal dan identifikasi masalah}

Survey awal dilakukan untuk mengetahui permasalahan nelayan di Kecematan Galesong terutama alat tangkap perahu dan sampan yang dioperasikan selama ini, dan ternyata permasalahan mereka adalah bagaimana merawat dan memperbaiki sarana penangkapan ikan tanpa menggangu operasional kapal tersebut.

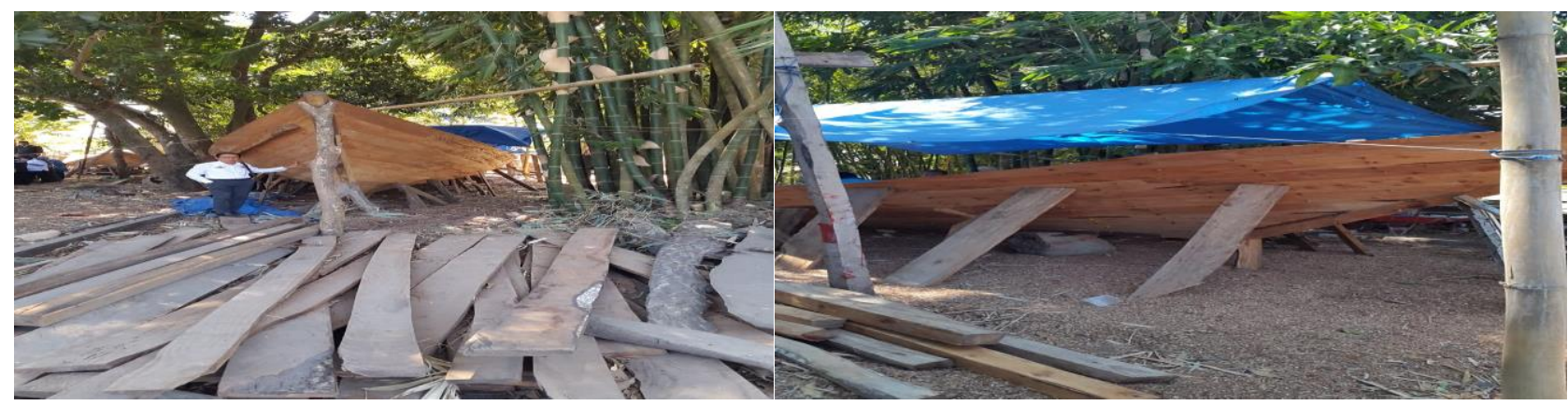

(a)

(b)

Gambar 5. Kegiatan pelaksanaan survey awal dan identifikasi permasalahan: a) Proses pemilihan papan kayu untuk sampan; b) Pemasangan gading-gading dalam dan pondasi mesin sampan nelayan

\subsection{Penyuluhan dan pelatihan pengeleman}

Kegiatan pengabdian praktek pengeleman Pada tanggal: 12 - 13 September 2019 (2 hari) di lokasi Lokasi wilayah mitra: Muh. Sayyed dg Ngempa, kecamatan galesong kabupaten Takalar. Tim berjumlah: 8 orang (Dosen dan Mahasiswa) dan peserta: 8 orang (Nelayan + pengamat perahu). Dengan rincian; Materi tentang material lem propant $=2$ orang; Materi tentang maksud dan tujuan pengabdian = 2 orang; Materi tentang hubungan lem (sebagai cat dan bahan kimia) dengan kayu (1 orang); Materi prakterk pengeleman sampan kayu $=3$ orang. Sehingga jumlah peserta $=8$ orang

Materi di berikan adalah:

1) Pentingnya perawatan sampan bagi peningkatan operasional sampan 
2) Penjelasan hubungan antara papan kulit sampan dengan gabung dan hubungan papan kulit sampan dengan lunas

3) Metode penempatan lem (2 jenis)

4) Metode pengukuran bidang lem yang akan dilem antara dua permukaan kulit kayu

5) Cara pemasangan lem dan penempelan kedua permukaan kayu

6) Mengecek hasil pengeleman kayu dan mencoba kekuatan kayu hasil pengeleman tersebut.

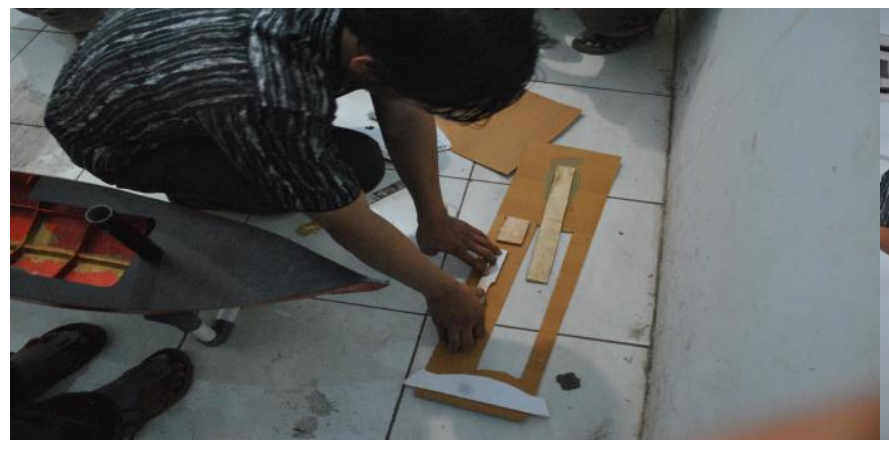

(a)

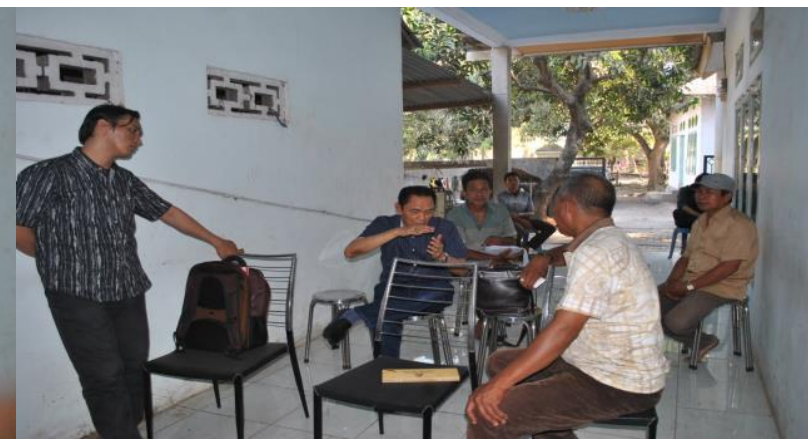

(b)

Gambar 6. Kegiatan penyuluhan dan pelatihan pengeleman: a) percobaan pengeleman pada benda kerja; b diskusi terkait hasil pengeleman pada benda kerja

5.3. Perhitungan Tegangan Hasil Pengeleman

1. Hubungan antara gading gading dan lembar kulit
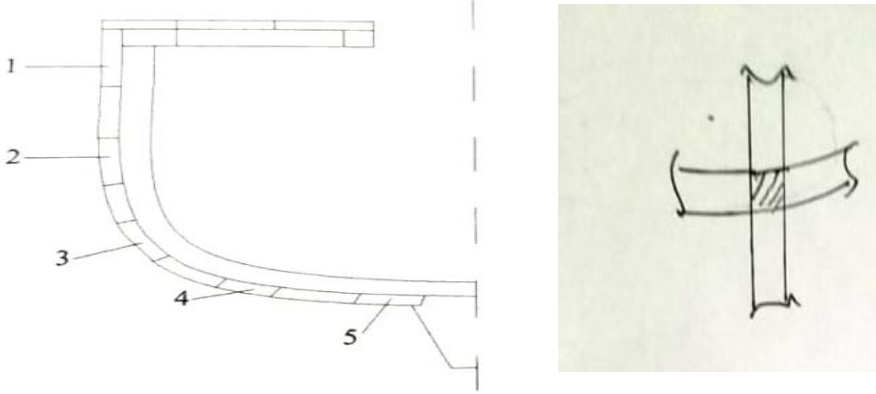

Ket:

1. Papan Lajur atas

2. Papan lajur sisi

3. Papan lajur bilga

4. Papan lajur alas

5. Papan lajur lunas

Gambar 7. Hubungan antara gading -gading dan lembar kulit dan detail sambungan

\begin{tabular}{|c|c|c|}
\hline No Gading & Luas rata - rata & P (beban) \\
\hline 1 & $2 \times 1.2=2.4 \mathrm{~cm}^{2}$ & $1590 \mathrm{~kg} / \mathrm{cm}^{2}$ \\
\hline 2 & $2 \times 1.8=3.6 \mathrm{~cm}^{2}$ & \\
\hline
\end{tabular}

$$
\begin{array}{rlrl}
\text { 1. } \sigma_{\text {tarik }} & =\frac{1590 \mathrm{~kg} / \mathrm{cm}^{2}}{2.4 \mathrm{~cm}^{2}} & \text { 2. } \sigma_{\text {tarik }} & =\frac{1590 \mathrm{~kg} / \mathrm{cm}^{2}}{3.6 \mathrm{~cm}^{2}} \\
= & 662,5 \mathrm{~kg} / \mathrm{cm}^{4} & =441,6 \mathrm{~kg} / \mathrm{cm}^{4}
\end{array}
$$


2. Hubungan antara lembar papan kulit dengan lunas /linggi haluan

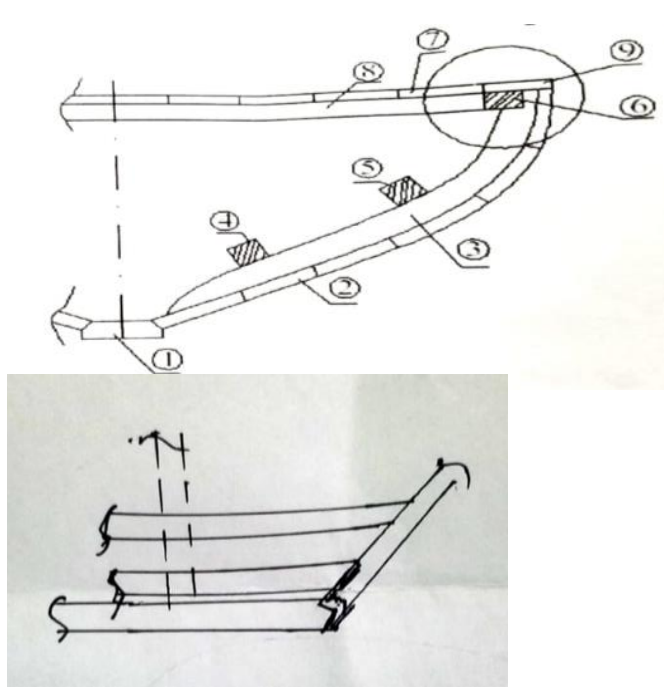

Ket:
1. Lunas
6. Papan kulit
2. Papan kulit
7. Papan geladak
3. Sulur
8. Balok Geladak
4. Galar Kim
5. Galar Tambahan
9.Papan tepi geladak

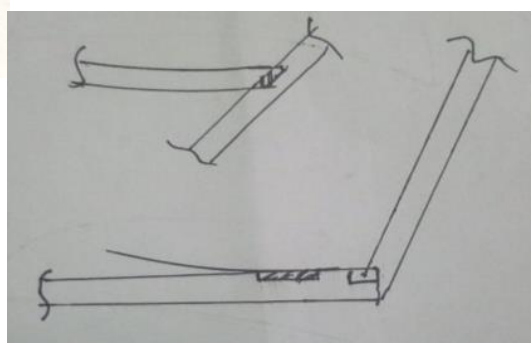

Gambar 8. Hubungan antara lembar papan kulit dengan lunas/linggi haluan dan detail sambungan

\begin{tabular}{|c|c|c|}
\hline No Gading & Luas rata - rata & P (beban) \\
\hline 1 & $2.4 \times 1.9=4.54 \mathrm{~cm}^{2}$ & $1590 \mathrm{~kg} / \mathrm{cm}^{2}$ \\
\hline 2 & $2.4 \times 2.0=4.8 \mathrm{~cm}^{2}$ & \\
\hline
\end{tabular}
1. $\sigma_{\text {tarik }}=\frac{1590 \mathrm{~kg} / \mathrm{cm}^{2}}{4.54 \mathrm{~cm}^{2}}$
2. $\sigma_{\text {tarik }}=\frac{1590 \mathrm{~kg} / \mathrm{cm}^{2}}{4.8 \mathrm{~cm}^{2}}$
$=350,220 \mathrm{~kg} / \mathrm{cm}^{4}$
$=331,25 \mathrm{~kg} / \mathrm{cm}^{4}$

\section{Kesimpulan}

Setelah melalui berbagai praktek bahwa penggunaan lem propant telah menunjukkan keunggulan, keunggulan ini secara teknis meningkatkan daya operasional perahu setiap saat terutama pemeliharaan sampan nelayan sebagai mode utama membawa berbagai jenis ikan dan hasil laut. Dari hasil praktek pengeleman kayu untuk papan lambung sampan menunjukkan bahwa tegangan geser yang dihasilkan cukup memadai dan memenuhi standar sistem dan tegangan (SNI) sehingga layak digunakan oleh para nelayan. Keuntungan lem adalah harga terjangkau dan tersedia dalam jumlah banyak. Ukuran permukaan lem sangat berpengaruh pada gaya geser (tarik) yang terjadi. Gaya geser yang paling rawan adalah pada sambungan papan, lunas, dan linggi haluan sampan.

\section{Ucapan Terima Kasih}

Penulis mengucapkan terima kasih kepada kepada Fakultas Teknik Universitas Hasanuddin, melalui pendanaan hibah LBE Pengabdian Masyarakat Sesuai SK Dekan Fakultas Teknik Unhas No: 4556/UN4.7.2/PL.01.10/2019 Tahun Anggaran 2019. Dan Terima kasih khususnya kepada Pimpinan Kelompok Nelayan Galesong (Muh Sayyed Dg. Nampa) sebagai Mitra Pengabdian di 
Kecamatan Galesong Kabupaten Takalar. Selanjutnya Terima Kasih kepada mahasiswa sebagai peserta kegiatan bersama, pengabdian masyarakat LBE (Labo-Based Education) Hidrodinamika Kapal Departemen Teknik Perkapalan FT-UH yang telah membantu selama proses kegiatan dimulai dari survei awal sampai akhir kegiatan pengabdian.

\section{Daftar Pustaka}

Fyson J. 1985. Design of Small Fishing Vessel. England: Fishing News.

Iskandar BH, Novita Y. 2000. Tingkat Teknologi Pembangunan Kapal Ikan Kayu Tradisional di Indonesia. Buletin PSPS Volume IX No.2. Departemen PSP FPIK IPB. Hal 53-67.

Azis Abdul Karim, Thesis S2. Karakter kekuatan material kayu untuk kapal, 2010.

Wikipedia Indonesia "Kabupaten Takalar" https://id.wikipedia.org/wiki/Kabupaten_Takalar. Bachtiar, Fauzi, "Uji kekuatan Mekanis dan Fisis Lem". Laboratorium PT. PAI. Probolinggo (2004).

P. Manik, Teknologi Pembuatan Kapal Kayu Laminasi, Universitas Diponegoro (1997). 